\title{
High-dose Chemotherapy with Stem Cell Rescue Provided Durable Remission for Classical Hodgkin Lymphoma-type Post-transplant Lymphoproliferative Disorder after Unrelated Cord Blood Transplantation: A Case Report and Review of the Literature
}

\author{
Hidehiro Itonaga ${ }^{1,2}$, Takeharu Kato ${ }^{2,3}$, Machiko Fujioka ${ }^{1,2}$, Masataka Taguchi ${ }^{2}$, \\ Hiroaki Taniguchi ${ }^{2}$, Yoshitaka Imaizumi ${ }^{1}$, Shinichiro Yoshida ${ }^{4}$, Hiroaki Miyoshi ${ }^{3}$, \\ Yukiyoshi Moriuchi ${ }^{2}$, Koichi Ohshima ${ }^{3}$ and Yasushi Miyazaki ${ }^{1}$
}

\begin{abstract}
An adult woman developed polymorphic post-transplant lymphoproliferative disorder (PTLD) 58 months after unrelated cord blood transplantation. She was treated successfully with chemotherapy and radiation therapy but presented with lymphadenopathy and splenomegaly 74 months after transplantation. A lymph node biopsy confirmed the diagnosis of nodular sclerosis type Hodgkin lymphoma (classical Hodgkin lymphoma [CHL]-type PTLD). After salvage therapy and hematopoietic stem cell harvesting, she was subsequently treated with consolidative high-dose chemotherapy with melphalan followed by stem cell rescue, which resulted in durable remission. High-dose chemotherapy using stem cell rescue has potential as a therapeutic option for subsequent CHL-type PTLD.
\end{abstract}

Key words: Classical Hodgkin lymphoma, post-transplant lymphoproliferative disorder, unrelated cord blood transplantation, high-dose chemotherapy

(Intern Med 56: 1873-1877, 2017)

(DOI: 10.2169/internalmedicine.56.7938)

\section{Introduction}

Post-transplant lymphoproliferative disorders (PTLDs) include histologically heterogeneous diseases from benign to malignant entities that develop in patients who have undergone organ transplantation or allogeneic hematopoietic stem cell transplantation (allo-HSCT). PTLDs have been divided into four subtypes according to the WHO classification: early lesions and polymorphic-, monomorphic-, and classical Hodgkin lymphoma types (1). Classical Hodgkin lymphoma-type PTLD (CHL-type PTLD) was previously reported to occur at the lowest frequency, approximately
$0.043 \%$, among allogeneic bone marrow transplant recipients (2). Therefore, the clinical course of CHL-type PTLD remains unclear.

We herein report a case of CHL-type PTLD that was successfully treated with high-dose chemotherapy using stem cell rescue derived from cord blood. Our results provide valuable insight into the management of CHL-type PTLD.

\section{Case Report}

A 59-year-old woman with secondary acute myeloid leukemia transformed from essential thrombocythemia underwent unrelated cord blood transplantation [total nucleated

\footnotetext{
${ }^{1}$ Department of Hematology, Nagasaki University Hospital, Japan, ${ }^{2}$ Department of Hematology, Sasebo City General Medical Center, Japan, ${ }^{3}$ Department of Pathology, School of Medicine, Kurume University, Japan and ${ }^{4}$ Department of Internal Medicine, National Hospital Organization Nagasaki Medical Center, Japan

Received for publication July 5, 2016; Accepted for publication November 7, 2016

Correspondence to Dr. Hidehiro Itonaga, itonaga-ngs@umin.ac.jp
} 


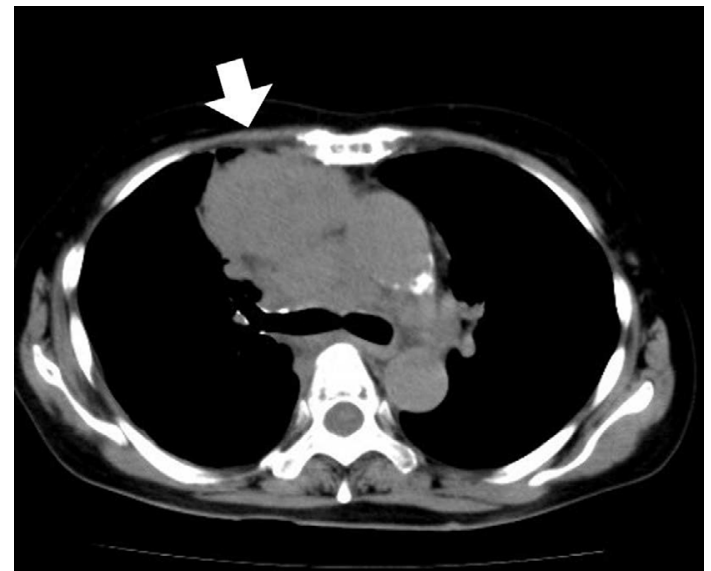

Figure 1. Computed tomography (CT) images showing an anterior mediastinal mass at the diagnosis of polymorphic post-transplant lymphoproliferative disorder (PTLD).

cell dose, $2.36 \times 10^{7}$ cells $/ \mathrm{kg}$; CD34-positive cell dose, $1.58 \times$ $10^{5}$ cells $/ \mathrm{kg}$; human leukocyte antigen (HLA) 2 loci mismatched (HLA-B and -DRB1 loci were serologically mismatched), from a male donor] in the non-remission stage after chemotherapy using reduced-intensity pre-transplant conditioning (fludarabine $150 \mathrm{mg} / \mathrm{m}^{2}$, melphalan $80 \mathrm{mg} / \mathrm{m}^{2}$, and total body irradiation $4 \mathrm{~Gy}$ ). Tacrolimus was used as a single agent for graft-versus-host disease (GVHD) prophylaxis. Neutrophil and platelet counts in the peripheral blood reached $>0.5 \times 10^{9} / \mathrm{L}$ on day +20 and $>20 \times 10^{9} / \mathrm{L}$, respectively, without transfusions on day +39 . She achieved $100 \%$ donor chimerism, which was confirmed by an XY-fluorescence in situ hybridization (FISH) analysis of bone marrow cells. Limited-type chronic GVHD emerged after the discontinuation of tacrolimus on day +154 . The patient presented with chest pain 58 months after transplantation, for which she had not received any immunosuppressants. Computed tomography (CT) revealed an anterior mediastinal mass (Fig. 1). A needle biopsy confirmed the diagnosis of polymorphic PTLD, which showed diffuse effacement of the nodal architecture with mixed cell proliferation including immunoblasts expressing CD20 and PAX5, plasma cells, a small number of CD20-negative Reed-Stenberg (RS)-like cells, and CD3-positive lymphocytes; however, these cells were negative for CD30 and Epstein-Barr virus (EBV) (Fig. 2). The biopsy samples were too small to evaluate the origin of polymorphic PTLD cells by an XY-FISH analysis. The use of rituximab for PTLD was not approved at that time in Japan. Furthermore, immunohistochemical staining revealed that polymorphic PTLD included CD20-positive immunoblasts and CD3-positive lymphocytes but CD20negative RS-like cells, indicating that rituximab was less effective in treating this subtype of PTLD than other subtypes. Therefore, rituximab in combination with chemotherapy was not considered. Partial remission was achieved following 6 courses of chemotherapy (vincristine, cyclophosphamide, doxorubicin, and prednisone [CHOP]) and $40 \mathrm{~Gy}$ of radiation therapy.
She developed left hilar and left supraclavicular lymphadenopathies as well as splenomegaly without the use of immunosuppressants 74 months after transplantation. A biopsy specimen of the supraclavicular lymph node showed the presence of nodular sclerosis-type Hodgkin lymphoma with RS cells. Immunohistochemical staining revealed that the RS cells were positive for CD15, CD30, PAX5, Epstein-Barr encoding region (EBER), and EBV latent membrane protein 1 (LMP1) and negative for CD3, CD20, and EBV nuclear antigen 2 (EBNA2) (Fig. 3A-F), which indicated type 2 latency according to the EBV antigen expression pattern in infected memory B cells. A FISH analysis showed that the RS cells did not have the chromosome Y signal (e.g. one or two chromosome $\mathrm{X}$ signals), while small-sized lymphocytes in the background had chromosome X and Y signals (e.g. XYtype) (Fig. 3G and H). She received three courses of salvage chemotherapy (etoposide, cytarabine, cisplatin, and prednisone [ESHAP]), and peripheral blood hematopoietic stem cells (PBSCs) derived from cord blood were harvested using granulocyte colony-stimulating factor mobilization. Since the tumor regression was $-33.5 \%$ in the sum of the product of greatest diameters (SPD) on CT after an additional 4 cycles of chemotherapy, she was judged to have achieved stable disease for CHL-type PTLD according to the established response criteria (3). High-dose melphalan treatment (180 mg/ $\mathrm{m}^{2}$ ) was then initiated, followed by PBSC rescue (CD34positive cells, $4.24 \times 10^{6}$ cells $/ \mathrm{kg}$ ). Neutrophil engraftment and platelet recovery were achieved on days +9 and +101 , respectively. A FISH analysis of peripheral blood cells revealed that $99.8 \%$ had the XY signal. Partial remission was observed after engraftment, with a $63.6 \%$ reduction in the tumor SPD on CT (Fig. 4). Severe complications such as infection and organ failure did not occur after high-dose chemotherapy. There were no clear signs of GVHD without the use of immunosuppressive agents after PBSC rescue. Since a $72.3 \%$ reduction in the tumor SPD without the appearance of new lesions was observed on CT on day +777 after stem cell rescue, partial remission was deemed to have been maintained without any symptoms to indicate the relapse of PTLD.

\section{Discussion}

Difficulties were associated with confirming the origin of $\mathrm{RS}$ cells in the present case. In most cases of PTLDs after allo-HSCT, proliferative lymphocytes are of donor origin (4), while those of recipient origin are very rare (5). The results of the FISH analysis in this case suggested two possibilities: the RS cells were derived either from (i) recipient cells (female) or from (ii) donor cells (male) with the loss of the $\mathrm{Y}$ chromosome as a cytogenetic abnormality. Although it was not possible to identify the cell origin of the preceding polymorphic PTLD by an XY-FISH analysis, the origin of the CD20-negative RS-like cells is of interest. Since identifying the origins of the RS-like cells in polymorphic PTLD and CHL-type PTLD may be helpful for obtaining a clearer 

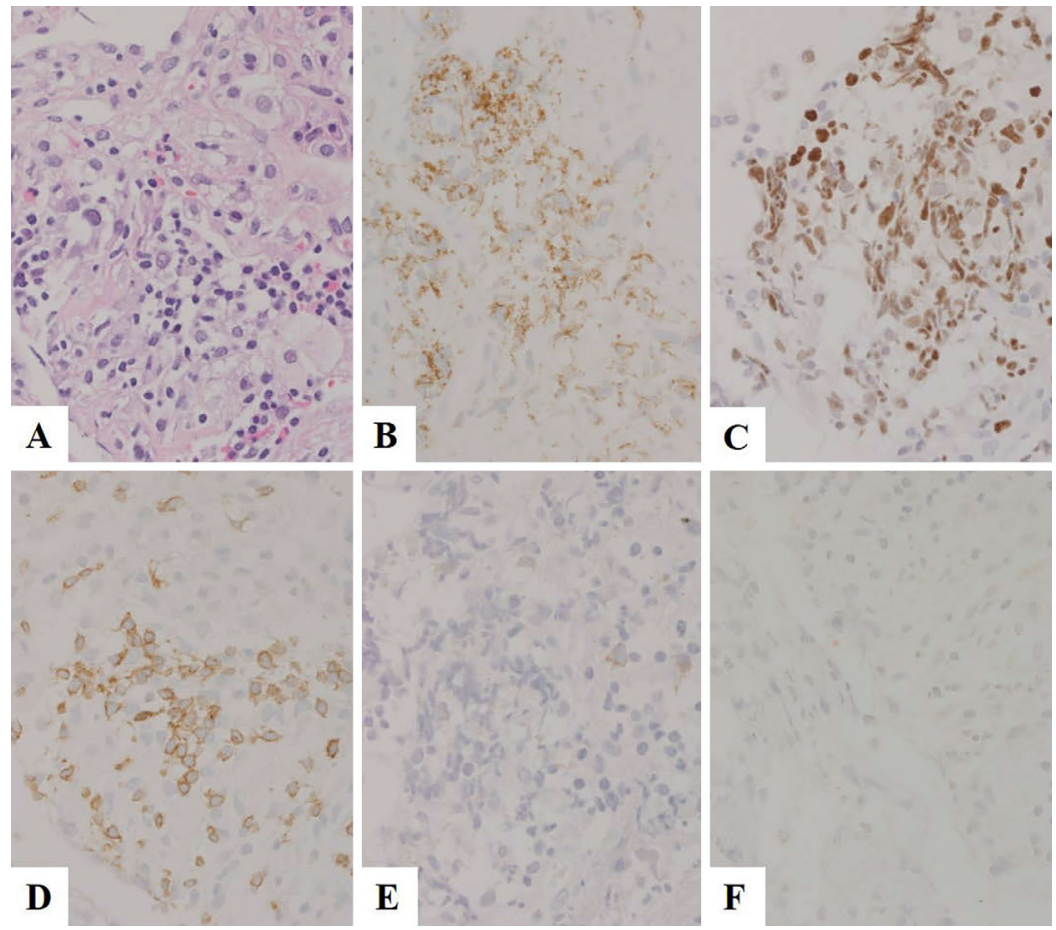

Figure 2. The pathological diagnosis of polymorphic PTLD. A needle biopsy showed mixed cell infiltration (A: Hematoxylin and Eosin staining, $\times 600)$, including immunoblasts expressing CD20 (B: $\times 600)$ and PAX5 (C: ×600), CD3-positive lymphocytes (D: $\times 600)$, and no CD30-positive cells $(\mathrm{E}: \times 600)$ or Epstein-Barr virus (EBV)-encoded small RNA (EBER)-positive cells (F: $\times 600)$.
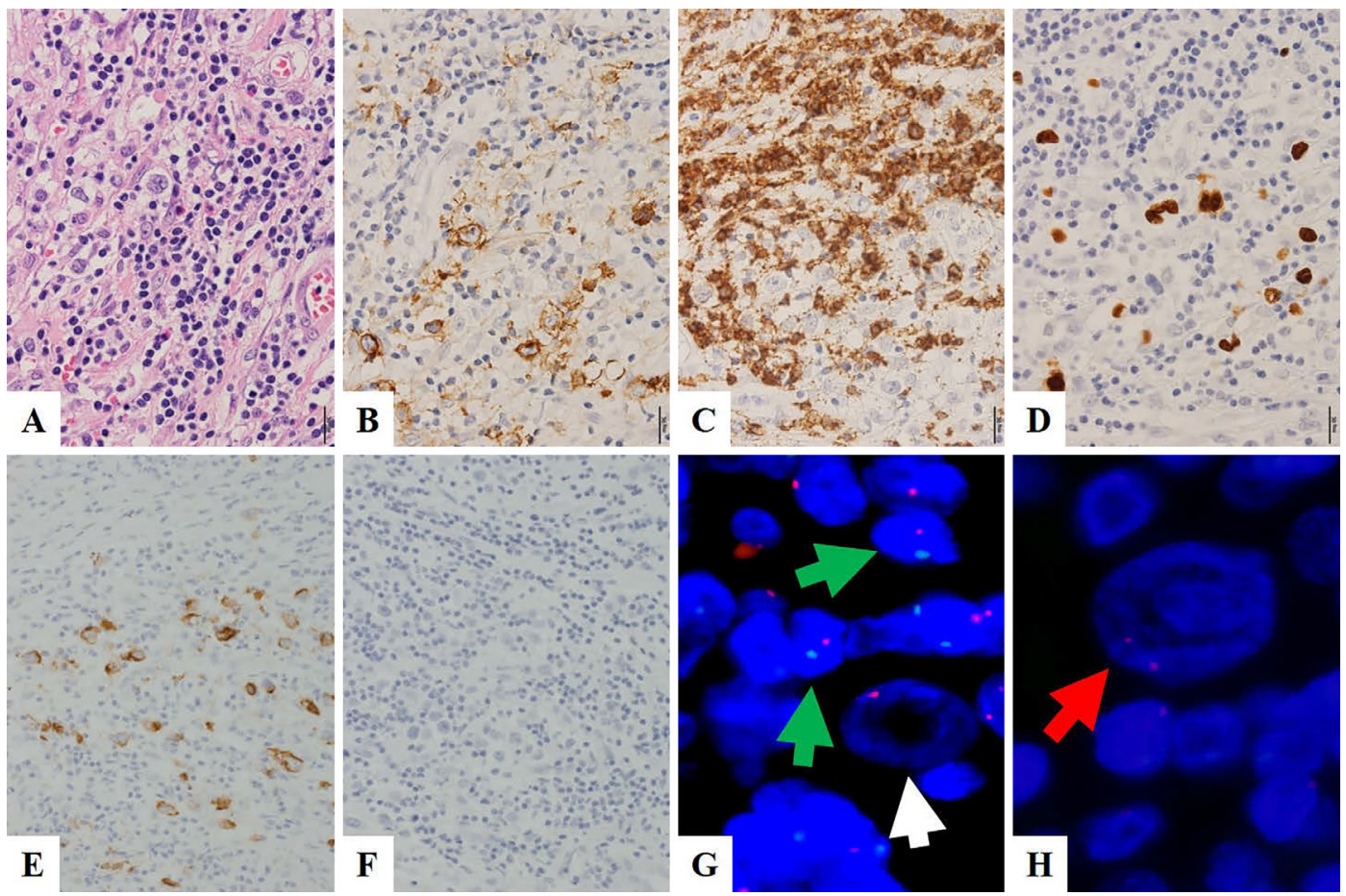

Figure 3. The pathological diagnosis of classical Hodgkin lymphoma-type PTLD (CHL-type PTLD). A supraclavicular lymph node biopsy revealed a polymorphous lymphoid infiltrate with a large number of Reed-Sternberg (RS) cells (A: Hematoxylin and Eosin staining, $\times 600$ ), which showed specific positivity for $\mathrm{CD30}(\mathrm{B}: \times 600)$ and negativity for $\mathrm{CD20}(\mathrm{C}: \times 600)$; in situ hybridization revealed positivity for EBER (D: $\times 600)$ and EBV latent membrane protein 1 (LMP1) (E: $\times 600)$, and negativity for EBV nuclear antigen 2 (EBNA2) (F: x600). An XY-fluorescence in situ hybridization analysis showed that $\mathrm{RS}$ cells had one (A: white arrow) or two (B: red arrow) red chromosome $\mathrm{X}$ signals, while small-sized lymphocytes had one red chromosome $\mathrm{X}$ signal and one green chromosome Y signal (A: green arrow) (G and $\mathrm{H})$. 

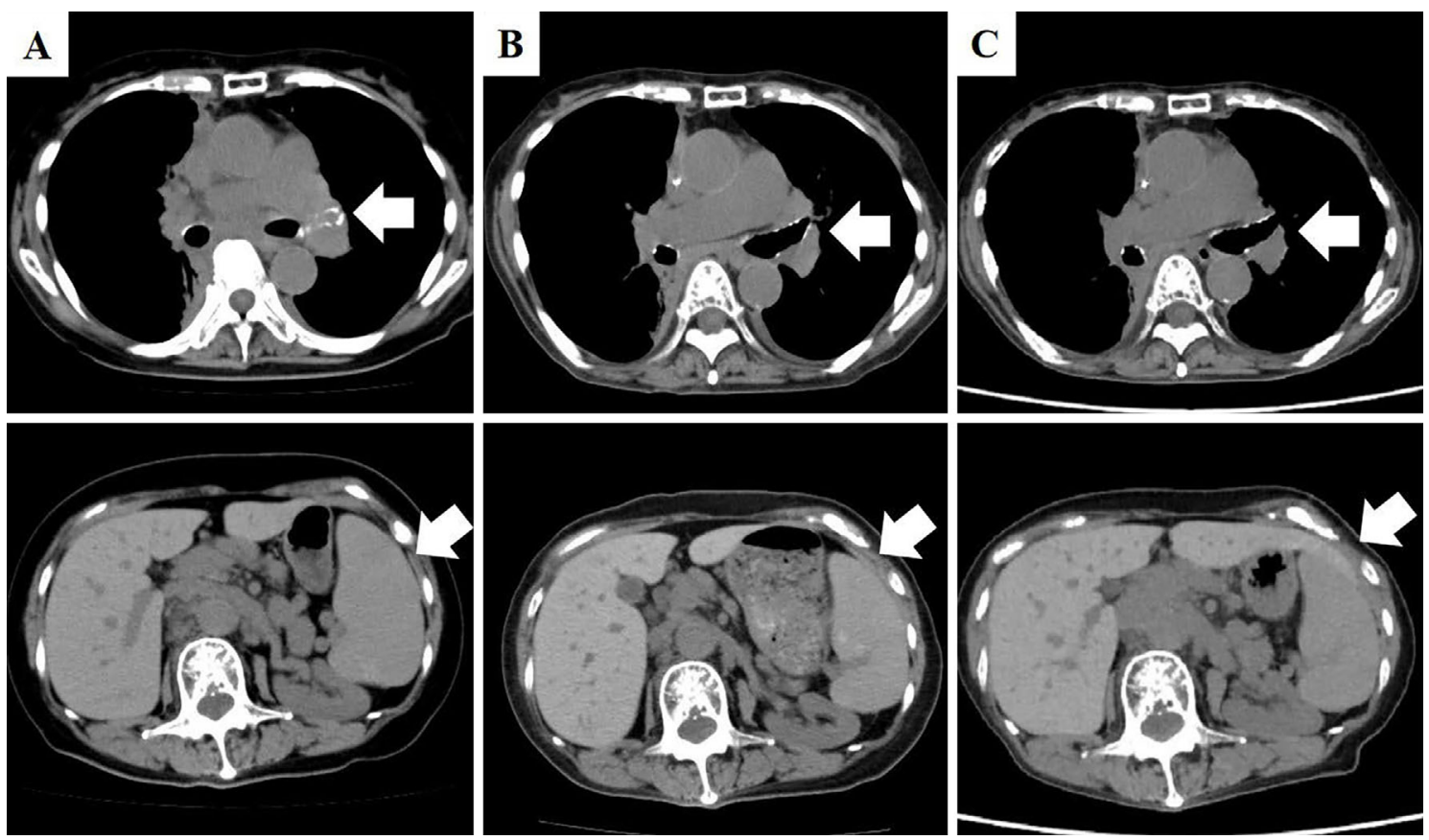

Figure 4. A CT scan showing left-hilar lymphadenopathies and splenomegaly (spleen length 9.9 cm) at the diagnosis of CHL-type PTLD (A). A CT scan demonstrating the resolution of left-hilar lymphadenopathies and splenomegaly (spleen length $9.0 \mathrm{~cm}$ ) before high-dose chemotherapy (B) and further resolution of stenosis of the trachea due to left-hilar lymphadenopathies and splenomegaly (spleen length $7.5 \mathrm{~cm}$ ) after high-dose chemotherapy with stem cell rescue (C).

Table. Summary of High-dose Chemotherapy Using Stem Cell Rescue for Post-transplant Lymphoproliferative Disorders.

\begin{tabular}{|c|c|c|c|c|c|c|c|c|c|}
\hline $\begin{array}{l}\text { Reference } \\
\text { case }\end{array}$ & $\begin{array}{l}\text { Age at } \\
\text { PTLD } \\
\text { diagnosis }\end{array}$ & Gender & $\begin{array}{l}\text { Allograft } \\
\text { type }\end{array}$ & PTLD type & $\begin{array}{l}\text { Status of } \\
\text { PTLD at } \\
\text { ASCT }\end{array}$ & $\begin{array}{l}\text { High-dose } \\
\text { chemotherapy } \\
\text { regimen }\end{array}$ & $\begin{array}{l}\text { Response } \\
\text { to ASCT }\end{array}$ & Survival & $\begin{array}{l}\text { Patient } \\
\text { status }\end{array}$ \\
\hline 6 & 66 & M & Heart & $\begin{array}{l}\text { Monomorphic type } \\
\text { (DLBCL) }\end{array}$ & 2nd PR & BEAC & $\mathrm{CR}$ & $\begin{array}{l}\text { Not } \\
\text { reported }\end{array}$ & Alive \\
\hline 7 & 26 & $\mathrm{M}$ & Kidney & $\begin{array}{l}\text { Monomorphic type } \\
\text { (DLBCL) }\end{array}$ & Relapse & Melphalan & $\mathrm{CR}$ & 4 years & Alive \\
\hline 8 & 4 & $\mathrm{~F}$ & Liver & $\begin{array}{l}\text { Monomorphic type } \\
\text { (T-cell lymphoma) }\end{array}$ & 2nd PR & BEAM & $\mathrm{CR}$ & 3.5 years & Alive \\
\hline Present case & 59 & $\mathrm{~F}$ & Cord blood & CHL type & SD & Melphalan & PR & $\begin{array}{l}2.1 \text { years } \\
(777 \text { days })\end{array}$ & Alive \\
\hline
\end{tabular}

DLBCL: diffuse large B-cell lymphoma, CHL: classical Hodgkin lymphoma, CR: complete remission, PR: partial remission, SD: stable disease, BEAC: carmustine, etoposide, cytarabine, and cyclophosphamide, BEAM: carmustine, etoposide, cytarabine, and melphalan

understanding of the development of these PTLDs, further analyses of more cases of CHL-type PTLD following polymorphic PTLD are needed.

CHL-type PTLD was previously reported to develop in recipients with other preceding PTLD subtypes, mainly polymorphic-type PTLD (6); however, difficulties were associated with clarifying the relationship between preceding polymorphic-type and CHL-type PTLDs. In our case, although preceding polymorphic-type PTLD included a small number of large cells as immunoblasts with the expression of PAX5, the immunohistochemical examination did not reveal any expression of CD30 or EBER, indicating a lesscommon manifestation of these cells between polymorphictype and CHL-type PTLDs. Based on the positive conversion of the EBV antigen on large cells in CHL-type PTLD,
EBV infection in tumor cells appears to have promoted the transformation of PTLD in our case. To clarify the relationship between polymorphic-type and CHTL-type PTLDs, further molecular analyses on the nature of tumor cells in PTLDs are required. For example, the presence of immunoglobulin gene rearrangements in the tumor cells of these two PTLDs is of interest (7).

Based on these findings in addition to the clinical course of the present case, a re-biopsy for subsequent PTLD was helpful in the selection of an appropriate salvage therapy, as rituximab may not be a feasible option for CD20-negative RS cells. However, optimum therapeutic strategies have not yet been established for subsequent PTLD after conventional chemotherapy (4). Only limited findings are available for high-dose chemotherapy using stem cell rescue for subse- 
quent PTLD in recipients after organ transplant, as summarized in Table (8-10). Notably, the present case confirmed that an adequate number of granulocyte colony-stimulating factor-mobilized peripheral blood hematopoietic stem cells derived from the donor could indeed be obtained, even in recipients after allo-HSCT. The present case may support high-dose chemotherapy with stem cell rescue as a promising option for patients after allo-HSCT; however, concerns have been expressed regarding increases in the risk of treatment toxicity due to a previous history of intensive chemotherapies.

The authors state that they have no Conflict of Interest (COI).

\section{Acknowledgement}

Author contributions: H.I.: Clinical management, data analysis/interpretation, and drafting the manuscript; T.K., H.M., and K.O.: Pathological evaluation and critical revision of the manuscript; M.F., M.T., H.T., and Y. Moriuchi: Clinical management and critical revision of the manuscript; Y.I. and S.Y.: data analysis/interpretation and critical revision of the manuscript; Y. Miyazaki: Critical revision and final approval of the manuscript.

\section{References}

1. Swerdlow SH, Campo E, Harris L, et al. Post-transplant lymphoproliferative disorders. In: WHO Classification of Tumours of Haematopoietic and Lymphoid Tissues. Swerdlow S, Campos E, Harris L, et al, Eds. IARC press, World Health Organization, Lyon, France, 2008: 343-349.

2. Rowlings PA, Curtis RE, Passweg JR, et al. Increased incidence of Hodgkin's disease after allogeneic bone marrow transplantation. J
Clin Oncol 17: 3122-3127, 1999.

3. Cheson BD, Pfistner B, Juweid ME, et al. Revised response criteria for malignant lymphoma. J Clin Oncol 25: 579-586, 2007.

4. Heslop HE. How I treat EBV lymphoproliferation. Blood 114: 4002-4008, 2009.

5. Au WY, Lie AK, Lee CK, et al. Late onset post-transplantation lymphoproliferative disease of recipient origin following cytogenetic relapse and occult autologous haematopoietic regeneration after allogeneic bone marrow transplantation for acute myeloid leukaemia. Bone Marrow Transplant 28: 417-419, 2001.

6. Basso S, Zecca M, Calafiore L, et al. Successful treatment of a classic Hodgkin lymphoma-type post-transplant lymphoproliferative disorder with tailored chemotherapy and Epstein-Barr virusspecific cytotoxic $\mathrm{T}$ lymphocytes in a pediatric heart transplant recipient. Pediatr Transplant 17: E168-E173, 2013.

7. Marafioti T, Hummel M, Foss HD, et al. Hodgkin and reedsternberg cells represent an expansion of a single clone originating from a germinal center B-cell with functional immunoglobulin gene rearrangements but defective immunoglobulin transcription. Blood 95: 1443-1450, 2000.

8. Malhotra B, Rahal AK, Farhoud H, Moore DF Jr, Kallail KJ. Treatment of recurrent posttransplant lymphoproliferative disorder with autologous blood stem cell transplant. Case Rep Transplant 2015: 801082, 2015.

9. Bobey NA, Stewart DA, Woodman RC. Successful treatment of posttransplant lymphoproliferative disorder in a renal transplant patient by autologous peripheral blood stem cell transplantation. Leuk Lymphoma 43: 2421-2423, 2002.

10. Williams KM, Higman MA, Chen AR, et al. Successful treatment of a child with late-onset T-cell post-transplant lymphoproliferative disorder/lymphoma. Pediatr Blood Cancer 50: 667-670, 2008.

The Internal Medicine is an Open Access article distributed under the Creative Commons Attribution-NonCommercial-NoDerivatives 4.0 International License. To view the details of this license, please visit (https://creativecommons.org/licenses/ by-nc-nd/4.0/).

(C) 2017 The Japanese Society of Internal Medicine http://www.naika.or.jp/imonline/index.html 